RESEARCH

\title{
Serum thyroglobulin evaluation on LC-MS/MS and immunoassay in TgAb-positive patients with papillary thyroid carcinoma
}

\author{
Eijun Nishihara1, Yoshitaka Hobo², Akira Miyauchi', Yasuhiro Ito', Miyoko Higuchi', Mitsuyoshi Hirokawa1, \\ Mitsuru Ito', Shuji Fukata1, Mitsushige Nishikawa1 and Takashi Akamizu1
}

${ }^{1}$ Kuma Hospital, Center for Excellence in Thyroid Care, Kobe, Japan

2ASKA Pharmamedical Co., Ltd. Fujisawa, Japan

Correspondence should be addressed to E Nishihara: nishihara@kuma-h.or.jp

\begin{abstract}
Objective: This study aimed to elucidate disproportionately low serum thyroglobulin (Tg) values in Tg antibody (TgAb)-positive patients with structural recurrence of papillary thyroid carcinoma (PTC) using liquid chromatography-tandem mass spectrometry (LCMS/MS).

Design: A retrospective study was performed on 176 patients in whom Tg and TgAb levels were measured between 2016 and 2021. Several comprehensive analyses of Tg-LC-MS/ MS with an electrochemiluminescence immunoassay for Tg (Tg-ECLIA) were conducted using serum samples.

Methods: TgAb-positive patients who underwent total thyroidectomy with multiple lung metastases due to PTC were evaluated using Tg-LC-MS/MS and Tg-ECLIA. Tg expression in lymph node metastases and metastatic lesions was evaluated by immunohistochemistry and Tg levels of aspiration washouts were also evaluated. Two in vitro assays were performed to elucidate TgAb interference.

Results: $\mathrm{Tg}$ concentrations of negative TgAb in both assays were similar $\left(\mathrm{R}^{2}=0.99 ; n=52\right)$. Patients with structural recurrence showed higher Tg values with Tg-LC-MS/MS than with Tg-ECLIA. The undetectable proportion was significantly lower with Tg-LC-MS/MS (31.6\%, $6 / 19)$ than with Tg-ECLIA (68.4\%, 13/19; $P=0.023)$. The spike-recovery rate and $\mathrm{Tg}$ concentrations determined by the serum mixture text $(n=29)$ were significantly reduced to $75.0 \%(118.3-88.7 \%)$ and $81.3 \%$ (107.0-87.0\%), respectively, with TgAb using Tg-ECLIA (both $P<0.001)$ confirming assay interference but not using Tg-LC-MS/MS (91.8-92.3\%, $P=0.77$ and $98.4-100.8 \%, P=0.18$, respectively).

Conclusions: TgAb had no effect on the Tg-LC-MS/MS assay but yielded 19-25\% lower values in Tg-ECLIA. Tg-LC-MS/MS is preferable for monitoring serum Tg levels in TgAbpositive patients, although those with structural recurrence often had disproportionally low $\mathrm{Tg}$ values.
\end{abstract}
Key Words
- serum thyroglobulin
- interference with TgAb
- LC-MS/MS
- structural recurrence 


\section{Introduction}

Thyroglobulin (Tg) is a thyroid-specific protein, and its serum levels are useful for monitoring patients with differentiated thyroid carcinomas (DTCs) who underwent total thyroidectomy. However, anti-Tg antibodies (TgAb) are present in approximately $25 \%$ of patients with DTCs $(1,2,3)$. When using currently commercially available immunoassays, which are the most sensitive for measuring $\mathrm{Tg}, \operatorname{Tg} A b$ can mask the epitopes by competing reagent antibodies for $\mathrm{Tg}$. This interference with $\mathrm{TgAb}$ may lead to $\mathrm{Tg}$ values that are lower than expected or even undetectable. This Tg underestimation is considered the most serious clinical problem for the clinical follow-up of postoperative patients with DTCs.

Liquid chromatography-tandem mass spectrometry (LC-MS/MS) for Tg quantification has emerged as an alternative method that may not be influenced by TgAb. This method is based on specific peptide quantitation following tryptic digestion of all proteins, including TgAb and immunocapture of Tg-specific peptides (4). Among various $\mathrm{Tg}$ peptides following cleavage at lysine or arginine with trypsin, two specific peptides, VIFDANAPVAVR and FSPDDSAGASALLR, have been reported to be reliable targets for Tg-LC-MS/MS $(5,6)$. Although the sensitivity of Tg-LC-MS/MS (approximately $3 \mathrm{ng} / \mathrm{mL}$ ) was insufficient for clinical use (5), recently improved reagents and instruments have conferred an analytical sensitivity of $4-0.5 \mathrm{ng} / \mathrm{mL}(7,8)$. This improved sensitivity of Tg-LC-MS/ MS has been used to evaluate structural recurrence in patients with thyroid cancer and positive $\operatorname{Tg} A b$ in several clinical trials $(6,9,10)$. However, no clear advantage has been proven for Tg-LC-MS/MS over immunoassays because of undetectable $\mathrm{Tg}$ values in approximately $40 \%$ of patients with distant metastases.

In this study, we improved the immunocapture step of the FSPDDSAGASALLR peptide for Tg-LC-MS/MS to efficiently examine serum $\mathrm{Tg}$ values in clinical practice. To clarify the potential impact of Tg measurement on structural recurrence in $\mathrm{TgAb}$-positive patients with papillary thyroid carcinoma (PTC), we compared the $\mathrm{Tg}$ values of our $\mathrm{Tg}$-LC-MS/MS with a commercially available electrochemiluminescence immunoassay for $\mathrm{Tg}$ (Tg-ECLIA). Furthermore, we elucidated the degree of interference by $\operatorname{Tg} \mathrm{Ab}$ in these assay systems using the two in vitro tests described below.

\section{Materials and methods}

\section{Samples and study groups}

Serum samples of total of 176 patients were chosen, in whom $\mathrm{Tg}$ and $\mathrm{TgAb}$ were measured as part of their routine clinical care at Kuma Hospital between 2016 and 2021. Tg and TgAb were measured using the ECLIA method, as described below. Samples were stored at $-80^{\circ} \mathrm{C}$ until analysis for the present study. Serum samples of 158 patients satisfying the following five criteria were consecutively selected as groups A-E (Table 1). Groups A and B were used for comparative measurement of serum $\mathrm{Tg}$ levels using Tg-ECLIA and Tg-LC-MS/MS. Group A was comprised of 52 serum samples that were $\mathrm{TgAb}$-negative with low to moderate levels of $\operatorname{Tg}(<426 \mathrm{ng} / \mathrm{mL})$. Group B was comprised of 19 sera that were $\mathrm{TgAb}$-positive and a varying range of $\mathrm{Tg}$ from 19 patients with multiple pulmonary metastases from PTCs treated with total thyroidectomy and radioactive iodine. Samples included in groups C, D, and E were chosen to evaluate the extent of possible interference by $\operatorname{TgAb}$ using the following in vitro spike-recovery test and serum mixture test (Supplementary Table 1, see section on supplementary materials given at the end of this article). Group C was comprised of 29 serum samples that were $\mathrm{TgAb}$-negative and $\mathrm{Tg}<0.9 \mathrm{ng} / \mathrm{mL}$ from patients who underwent total thyroidectomy for multinodular goiter. Group D was comprised of 29 sera that were $\mathrm{TgAb}$-positive and $\mathrm{Tg}<0.9 \mathrm{ng} / \mathrm{mL}$ from patients who underwent total thyroidectomy for multinodular goiter with Hashimoto

Table 1 Five categorized groups consisting of 158 serum samples.

\begin{tabular}{|c|c|c|c|}
\hline \multirow[b]{2}{*}{ Group } & \multirow[b]{2}{*}{ Subjects $(n)$} & \multicolumn{2}{|c|}{ ECLIA } \\
\hline & & $\underline{\operatorname{TgAb}}$ & $\operatorname{Tg}(\mathrm{ng} / \mathrm{mL})$ \\
\hline A & Thyroid lobectomy or total thyroidectomy due to PTC (52) & Neg & $0.41-426$ \\
\hline $\mathrm{B}$ & Total thyroidectomy due to PTC with structural recurrence (19) & Pos & $<0.08-2.33$ \\
\hline C & Total thyroidectomy due to MNG (29) & Neg & $<0.9$ \\
\hline $\mathrm{D}$ & Total thyroidectomy due to MNG with Hashimoto's thyroiditis (29) & Pos & $<0.9$ \\
\hline $\mathrm{E}$ & $\begin{array}{l}\text { MNG (21) } \\
\text { Thyroid carcinomas (6) } \\
\text { Benign thyroid diseases: Graves' disease, subacute thyroiditis (2) }\end{array}$ & Neg & $>2000$ \\
\hline
\end{tabular}

PTC, papillary thyroid carcinoma; MNG, multinodular goiter.

https://etj.bioscientifica.com

https://doi.org/10.1530/ETJ-21-0041 (c) 2022 The authors Published by Bioscientifica Ltd.

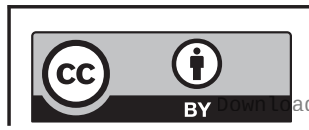

This work is licensed under a Creative Commons Attribution 4.0 International License. ded from Bioscientifica.com at 04/26/2023 10:40:25AM via free access 
thyroiditis. Group E was comprised of 29 sera that were $\mathrm{TgAb}$-negative with high levels of $\mathrm{Tg}>2000 \mathrm{ng} / \mathrm{mL}$. All sera were $1-2 \mathrm{~mL}$ since they were residual sera from routine clinical practice.

\section{Immunoassays of $\mathrm{Tg}$ and $\mathrm{TgAb}$}

Immunoassays for $\mathrm{Tg}$ and $\mathrm{TgAb}$ were performed using the ECLIA method, Elecsys Tg II, and Elecsys TgAb (Roche Diagnostics). The lower limit of quantification (LLOQ) for $\mathrm{Tg}$-ECLIA was $0.08 \mathrm{ng} / \mathrm{mL}$, and the cut-off value for $\mathrm{TgAb}$ was $28 \mathrm{IU} / \mathrm{mL}$.

\section{LC-MS/MS analysis procedure}

Tg, trypsin, and sodium deoxycholate (DOC) were purchased from Sigma-Aldrich. The internal standard peptide comprising the sequence $\mathrm{F}^{*}$ SPDDSAGASALLR (F* $\left[{ }^{13} \mathrm{C}_{9}\right]$, mass shift $9 \mathrm{Da}$ ) was synthesized by ASKA Pharmamedical Co., Ltd. (Fujisawa, Japan). Dithiothreitol (DTT) and trichloroacetic acid (TCA) were purchased from Nacalai Tesque (Kyoto, Honshu, Japan). Acetic and formic acids were purchased from FUJIFILM Wako Pure Chemical Industries (Osaka, Honshu, Japan). All other reagents used in the experiments were of high grade or equivalent.

Serum $(250 \mu \mathrm{L})$ was diluted with $250 \mu \mathrm{L}$ of pure water. Thirty microliters of 5\% DOC and $30 \mu \mathrm{L}$ of $20 \mathrm{mM}$ DTT solution were sequentially added to the sample and incubated at $60^{\circ} \mathrm{C}$ for $1 \mathrm{~h}$. After adding $10 \mu \mathrm{L}$ of $4 \mathrm{mg} / \mathrm{mL}$ trypsin solution, the mixture was further incubated for $2 \mathrm{~h}$. The enzymatic reaction that digested Tg to its specific peptide (FSP peptide) was quenched with $50 \mu \mathrm{L}$ of TCA, and an internal standard (IS) was added to it. After centrifugation for $5 \mathrm{~min}\left(2150 \mathrm{~g}, 20^{\circ} \mathrm{C}\right)$, the supernatant was purified with polyclonal anti-FSP peptide antibody using MonoSpin ProG (GL Sciences Inc., Tokyo, Japan), which is a spin-type column immobilized with protein $\mathrm{G}$. After purification, the FSP peptide and IS were quantified using LC-MS/MS.

An analysis was performed with heart-cutting 2D-LC-MS/MS using Agilent 1290 Infinity LC (Agilent) for HPLC and API5000 (AB SCIEX) for the MS/MS system. The mobile phase consisted of a gradient elution of $0.1 \%$ formic acid solution and acetonitrile for the first separation using ACQUITY UPLC HSS Cyano $(1.8 \mu \mathrm{m}, 100 \times 2.1 \mathrm{~mm}$ id) from Waters (Milford, MA, USA) and a gradient elution of $1 \mathrm{mM}$ acetic acid solution and methanol for the second separation using Triart C18 $(1.9 \mu \mathrm{m}, 50 \times 2.1 \mathrm{~mm}$ id) from YMC (Kyoto, Japan), with flow rates of 0.5 and $0.45 \mathrm{~mL} / \mathrm{min}$, respectively. The column temperature was set to $60^{\circ} \mathrm{C}$. The injection volume was $20 \mu \mathrm{L}$. Mass transitions monitored in the method were $\mathrm{m} / \mathrm{z} 704.1 / 587.0$ for the FSP peptide and $\mathrm{m} / \mathrm{z} 708.5 / 586.6$ for the IS.

The standard calibration curve was prepared with eight samples at concentrations of $0,0.4,1,4,20,40$, 200, and $400 \mathrm{ng} / \mathrm{mL}$. PBS was used as a surrogate matrix for standard samples. Peak integration and calculation of concentrations against the standard curve were performed using Analyst version 1.6 (AB SCIEX). The method was fully validated according to the FDA Bioanalytical Method Validation Guide and applied to the analysis of clinical samples. The mean CVs were $4.5 \%$ for the intra-assay and $5.7 \%$ for the inter-assay. A $0.4 \mathrm{ng} / \mathrm{mL} \mathrm{LLOQ,} \mathrm{the}$ lowest concentration of analyte in a sample that can be quantified reliably, was determined as the analyte signal of the LLOQ sample being at least five times the signal of a blank sample. The precision (\%CV) of the concentrations determined at the LLOQ was 10\%. The LC-MS/MS assays in this study were performed at ASKA Pharmamedical Co., Ltd. (Fujisawa, Japan).

\section{In vitro tests to evaluate possible interference of the measurements with TgAb}

\section{Spike-recovery test}

To evaluate $\mathrm{TgAb}$ interference, $50 \mu \mathrm{L}$ of standard $\mathrm{Tg}$ solution $(0.5 \mu \mathrm{g} / \mathrm{mL})$ was spiked into each of the $200 \mu \mathrm{L}$ serum samples with $\mathrm{Tg}<0.9 \mathrm{ng} / \mathrm{mL}$ and negative $\mathrm{TgAb}$ (group C) and to each of the $200 \mu \mathrm{L}$ serum samples with $\mathrm{Tg}<0.9 \mathrm{ng} / \mathrm{mL}$ and positive $\mathrm{TgAb}$ (group D), to obtain a final concentration of $100 \mathrm{ng} / \mathrm{mL}$ for $\mathrm{Tg}$. Each sample was kept at room temperature for $30 \mathrm{~min}$ and processed for Tg measurement using Tg-ECLIA and Tg-LC-MS/MS. $\mathrm{Tg}$ recovery was calculated as follows: (measured $\mathrm{Tg}$ concentration after addition of standard $\mathrm{Tg}(\mathrm{ng} / \mathrm{mL}) /$ $100 \mathrm{ng} / \mathrm{mL}) \times 100(\%)$. The comparative ratio (\%) was calculated as the median recovery rate defined as follows: $\mathrm{Tg} \mathrm{Ab} \times 100 /$ median recovery rate without $\mathrm{Tg} \mathrm{Ab}$.

\section{Serum mixture test}

As an assay to evaluate possible interference by $\operatorname{TgAb}$, each of $200 \mu \mathrm{L}$ of the 29 serum samples of patients with high $\mathrm{Tg}$ concentration and negative $\mathrm{TgAb}$ (group E) was randomly mixed with an equal amount of the 29 serum samples with $\mathrm{Tg}<0.9 \mathrm{ng} / \mathrm{mL}$ and negative $\mathrm{TgAb}$ (group C). Similar mixtures were also performed for the 29 serum samples with $\mathrm{Tg}<0.9 \mathrm{ng} / \mathrm{mL}$ and positive $\mathrm{TgAb}$ (group D). After mild vortexing, the 58 mixed samples were kept at room temperature for $30 \mathrm{~min}$. Serum Tg levels were then measured using Tg-ECLIA and Tg-LC-MS/MS. The change rate of Tg concentration was calculated as follows:

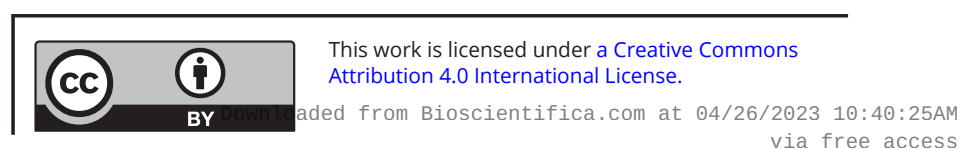


(Tg concentration of the mixed group $\mathrm{C}$ or D samples $(\mathrm{ng} / \mathrm{mL}) \times 2 / \mathrm{Tg}$ concentration of a group $\mathrm{E}$ sample $(\mathrm{ng} / \mathrm{mL})) \times 100(\%)$. The comparative ratio (\%) was calculated as the median recovery rate defined as follows: $\mathrm{Tg} \mathrm{Ab} \times 100 /$ median recovery rate without $\mathrm{Tg} \mathrm{Ab}$.

\section{Assessment of equilibrated Tg with TgAb}

To evaluate equilibrated $\mathrm{Tg}$ with $\mathrm{TgAb}$ dependent on reaction time, both spike-recovery and serum mixture tests were further assessed under three different conditions (at room temperature for $30 \mathrm{~min}$, at $4{ }^{\circ} \mathrm{C}$ for $24 \mathrm{~h}$, and at $4{ }^{\circ} \mathrm{C}$ for $72 \mathrm{~h}$ ) in each procedure. Serum samples of 18 patients were additionally used for analysis, including six samples compatible with groups C and D and the other six samples with negative $\mathrm{TgAb}$ and moderate $\mathrm{Tg}$ levels (around $100 \mathrm{ng} / \mathrm{mL}$ ) using the ECLIA method.

\section{Evaluation of $\mathrm{Tg}$ production}

In TgAb-positive patients with structural recurrence and undetectable Tg levels (Table 2), the following were added:

\section{Aspiration washout}

Aspiration biopsy of the cervical lymph node metastasis and measurement of $\mathrm{Tg}$ in the washout fluid of the needle with saline $(0.5 \mathrm{~mL})$ was performed.

\section{Tg immunohistochemistry}

After surgery, the thyroid and cervical lymph nodes were fixed in $10 \%$ neutral buffered formalin, and the specimens were embedded in paraffin. Serial sections (3- $\mu$ m thick) were cut from each paraffin block.

For six patients with structural recurrence but undetectable $\mathrm{Tg}$ values determined by Tg-ECLIA and Tg-LC-MS/MS, immunostaining for human Tg (mouse monoclonal, 1D4, 1:200, Leica Biosystems Newcastle, United Kingdom) was performed using the Leica Bondmax system (Leica Microsystems, Wetzlar, Germany) and a Bond Refine Kit (Leica Microsystems), according to the manufacturer's instructions.

\section{Statistical analysis}

Linear regression with the least-squares method was used to calculate the regression line equation and correlation coefficient. Differences in percentages between negative and positive $\mathrm{TgAb}$ samples in the serum mixture test and spike-recovery test were evaluated using the MannWhitney $U$ test. Comparisons of the detectable Tg samples between Tg-LC-MS/MS and Tg-ECLIA were performed using the chi-squared test. Statistical significance was set at $P<0.05$. Statistical analyses were performed using StatFlex version 6.0 (Artech Co. Ltd., Fukuoka, Japan).

The study protocol was approved by the Ethics Committee of Kuma Hospital (approval number: 2017091410). Informed consent was obtained from each patient prior to initiation of the study.

\section{Results}

Figure 1 shows the comparative $\mathrm{Tg}$ measurements between LC-MS/MS and ECLIA methods in group A. Tg concentrations in both assays were similar in negative $\operatorname{TgAb}\left(\mathrm{R}^{2}=0.99\right.$; Fig. 1A). A comparison of clinically lower $\mathrm{Tg}$
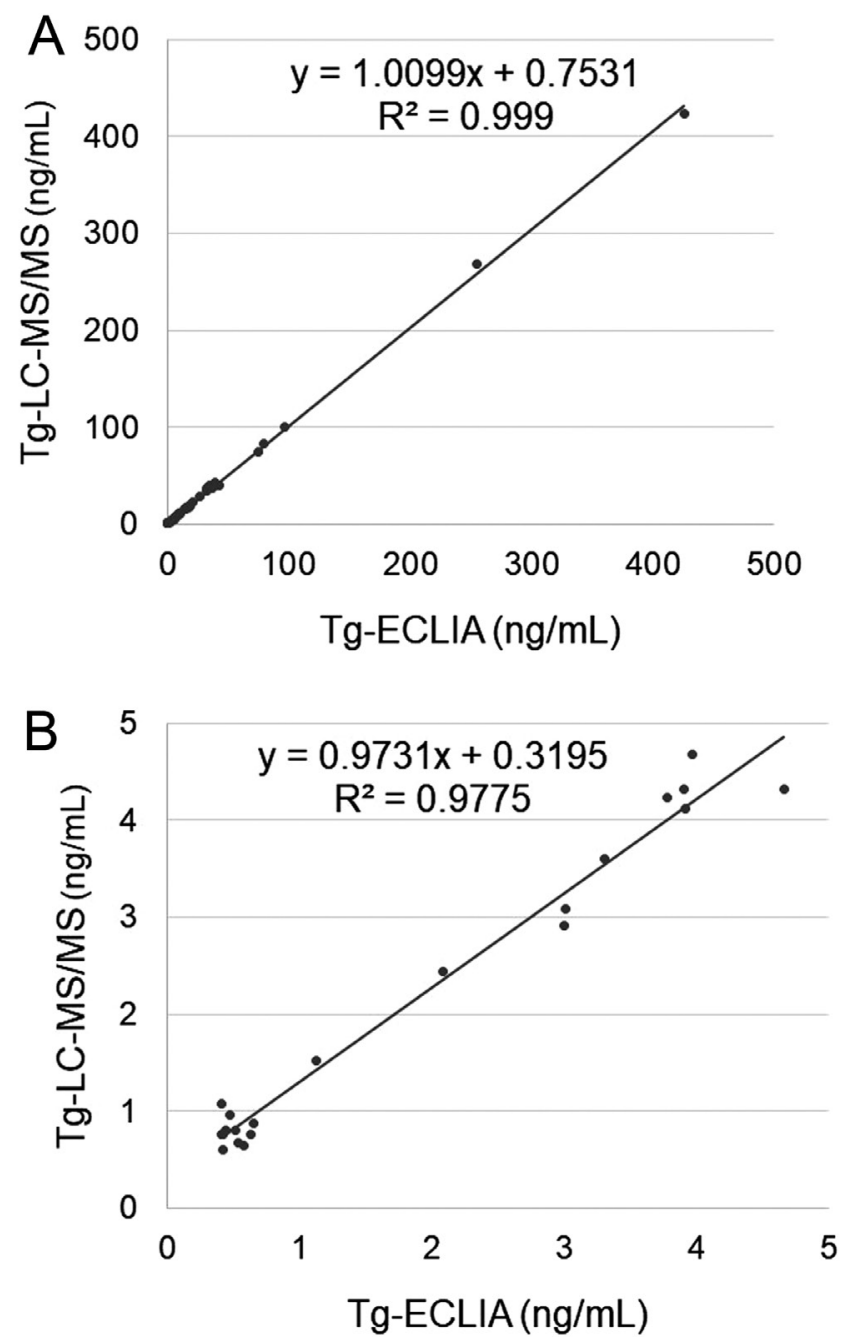

Figure 1

Comparison of serum Tg values with LC-MS/MS and ECLIA measurements in TgAb-negative patients. (A) Total patients ( $n=52$ ); (B) subpopulation with $<5 \mathrm{ng} / \mathrm{mL}$ in the ECLIA method $(n=21)$. 
Table 2 Serum Tg values measured with LC-MS/MS and ECLIA methods in TgAb-positive patients with structural papillary thyroid carcinoma.

\begin{tabular}{|c|c|c|c|}
\hline \multirow[b]{2}{*}{ Patient } & \multirow[b]{2}{*}{ TgAb (IU/mL) } & \multicolumn{2}{|c|}{$\mathbf{T g}(\mathrm{ng} / \mathrm{mL})$} \\
\hline & & Tg-LC-MS/MS & Tg-ECLIA \\
\hline 1 & $>4000$ & 3.40 & 1.01 \\
\hline 2 & $>4000$ & 1.72 & 0.77 \\
\hline 3 & $>4000$ & 0.80 & $<0.08$ \\
\hline 4 & $>4000$ & 0.44 & $<0.08$ \\
\hline 5 & $>4000$ & 0.40 & $<0.08$ \\
\hline 6 & $>4000$ & $<0.40$ & $<0.08$ \\
\hline 7 & $>4000$ & $<0.40$ & $<0.08$ \\
\hline 8 & $>4000$ & $<0.40$ & $<0.08$ \\
\hline 9 & 2830 & 0.76 & $<0.08$ \\
\hline 10 & 1805 & 0.44 & $<0.08$ \\
\hline 11 & 1190 & 1.36 & 0.9 \\
\hline 12 & 1013 & $<0.40$ & $<0.08$ \\
\hline 13 & 970.8 & 0.72 & $<0.08$ \\
\hline 14 & 283.9 & 1.32 & 0.39 \\
\hline 15 & 167.8 & $<0.40$ & $<0.08$ \\
\hline 16 & 133.4 & 1.08 & 0.34 \\
\hline 17 & 67.9 & 0.48 & $<0.08$ \\
\hline 18 & 58.8 & 3.68 & 2.33 \\
\hline 19 & 56.4 & $<0.40$ & $<0.08$ \\
\hline
\end{tabular}

concentrations $(<5 \mathrm{ng} / \mathrm{mL})$ also showed a good correlation coefficient and slope bias between both assays (Fig. 1B).

In the 19 TgAb-positive patients with multiple pulmonary metastases from PTC who had been treated with total thyroidectomy and radioactive iodine (group B), Tg was undetectable in Tg-ECLIA using 13 serum samples. Of these samples, six were undetectable in Tg-LC-MS/MS; however, seven were detectable (Table 2).

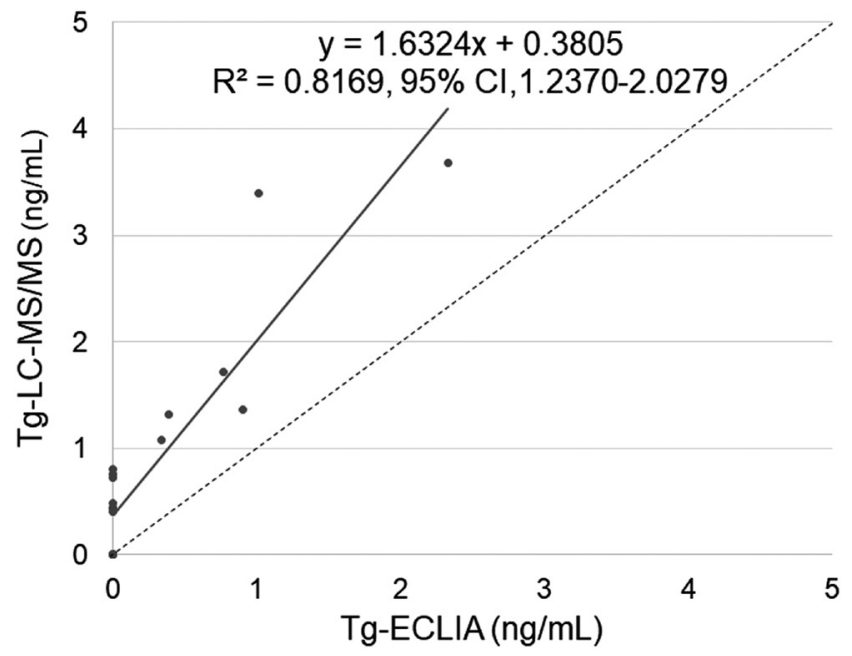

Figure 2

Highly detectable Tg with LC-MS/MS compared with ECLIA in TgAbpositive patients with structural disease of papillary thyroid carcinoma. Serum Tg values in patients ( $n=19$ ) with structural disease and positive TgAb using Tg-LC-MS/MS and Tg-ECLIA. The dotted lines indicate equal values between the Tg-LC-MS/MS and Tg-ECLIA.
Although $0.4 \mathrm{ng} / \mathrm{mL}$ LLOQ in Tg-LC-MS/MS was higher than that in Tg-ECLIA $(0.08 \mathrm{ng} / \mathrm{mL})$, the undetectable percentage $(31.6 \%, 6 / 19)$ in $\mathrm{Tg}$-LC-MS/MS was significantly lower than that $(68.4 \%, 13 / 19)$ in Tg-ECLIA $(P=0.023)$. These undetectable $\mathrm{Tg}$ values were not dependent on $\mathrm{TgAb}$ titer (Table 1 ). While only six samples showed detectable Tg in both assays, all $\mathrm{Tg}$ values obtained were higher with Tg-LC-MS/MS than with Tg-ECLIA (Fig. 2 and Table 2). However, these Tg values were disproportionally low, considering that these patients had structural disease recurrence of PTC. Among group A, five TgAb-negative patients who were treated with total thyroidectomy and radioactive iodine presented with multiple pulmonary metastases from PTCs. Their serum Tg levels were 6.7, 15.7, 16.6, 33.8, and $100.3 \mathrm{ng} / \mathrm{mL}$ with Tg-LC-MS/MS.

Immunohistochemical analysis of cervical lymph node metastases with conventional histology of PTC in six patients who had structural recurrence but undetectable $\mathrm{Tg}$ values in both assays showed that all samples were positive for Tg protein similar to the primary tumors in the thyroid (Fig. 3). In one patient (no. 17 in Table 2), who has developed cervical lymph node metastasis of PTC, Tg levels in the washout fluid after fine needle aspiration were $75.6 \mathrm{ng} / \mathrm{mL}$ with Tg-ECLIA and $78.7 \mathrm{ng} / \mathrm{mL}$ with Tg-LC-MS/MS, respectively, demonstrating production of $\mathrm{Tg}$ in the metastatic lesion.

To clarify the possible assay interference by $\operatorname{TgAb}$, we performed two in vitro studies. In the spike-recovery tests, the recovery rates of TgAb-positive samples in the Tg-ECLIA assay were diverse and significantly reduced to $75.0 \%$ compared with those of TgAb-negative samples (118.3$88.7 \%, P<0.001$; Fig. 4$)$. In contrast, the recovery rates in the $\mathrm{Tg}$-LC-MS/MS assay were not significantly different, irrespective of the presence or absence of $\operatorname{TgAb}(P=0.77)$, with a comparative ratio of $100.5 \%$ (Fig. 4).

In the serum mixture tests, target serum samples with high $\mathrm{Tg}$ and negative $\mathrm{TgAb}$ were mixed with $\mathrm{TgAb}$ positive sera. The change rates of $\mathrm{Tg}$ in the Tg-ECLIA assay were diverse and significantly reduced to $81.3 \%$ compared to those with TgAb-negative mixtures (107.0$87.0 \%, P<0.001$; Fig. 5). In contrast, these mixtures in the Tg-LC-MS/MS assay showed similar rates $(P=0.18)$, with a comparative ratio of $102.4 \%$ (Fig. 5). These in vitro studies showed that the extent of interference in Tg-ECLIA by $\mathrm{TgAb}$ resulted in a mild decrease in $\mathrm{Tg}$ values by $19-25 \%$ and that Tg-LC-MS/MS measurement was unaffected by $\mathrm{TgAb}$. Equilibration of $\mathrm{Tg}$ with $\mathrm{TgAb}$ for a longer time had little effect on both spike-recovery and serum mixture tests (Supplementary Tables 2 and 3).

This work is licensed under a Creative Commons Attribution 4.0 International License. 

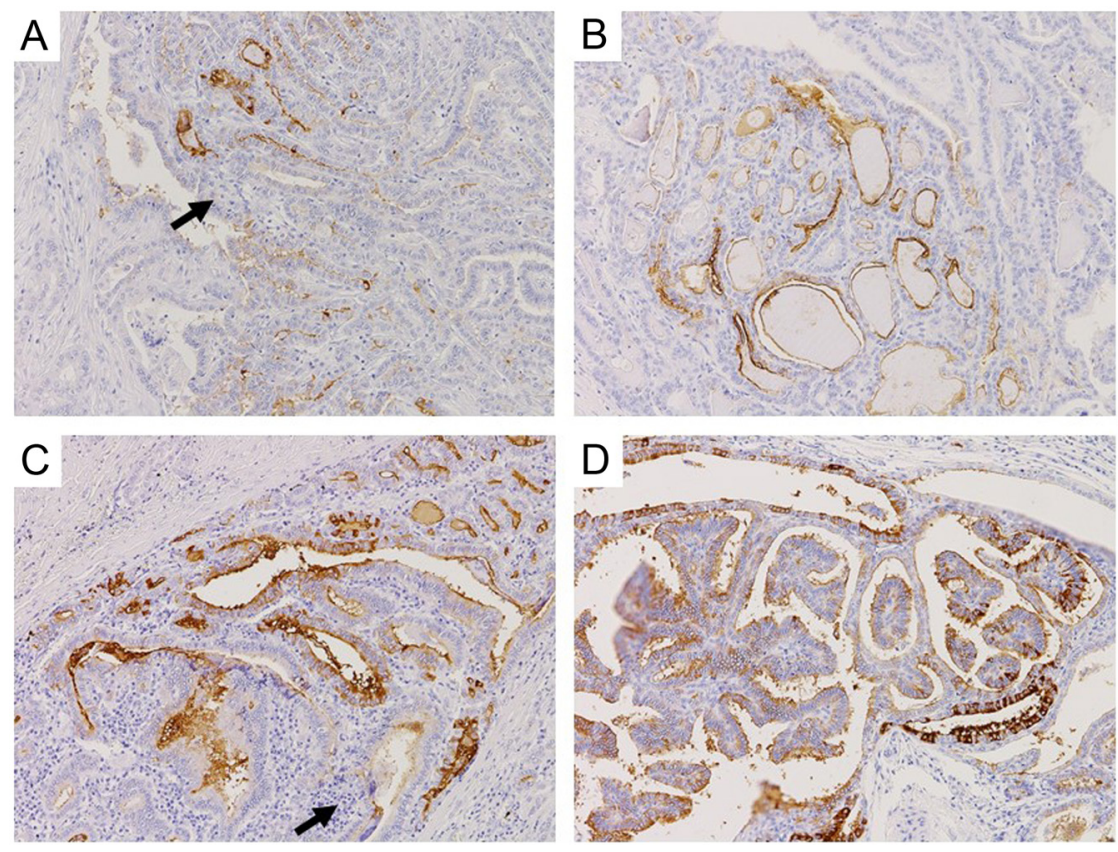

\section{Figure 3}

Immunohistochemical analysis of Tg expression in patients with structural disease and positive TgAb. Tg expression was detected at varied levels in conventional histology of PTC in the thyroid (A, C) and lymph node metastasis (B, D). Lymphocytic infiltration in the thyroid is indicated by arrows. $A$ and $B$, patient $12 ; C$ and $D$, patient 15 in Table 1. Original magnification: $\times 10(A-D)$.

\section{Discussion}

In this study, we found that patients with structural recurrence of PTCs and positive $\mathrm{TgAb}$ had undetectable $\mathrm{Tg}$ values of $68.4 \%$ with Tg-ECLIA and $31.6 \%$ with Tg-LC-MS/MS. Moreover, all detectable Tg values in the $\mathrm{Tg}$-LC-MS/MS assay were disproportionately low for patients with pulmonary metastases of PTC. These data are very similar to those of three previous reports showing undetectable Tg

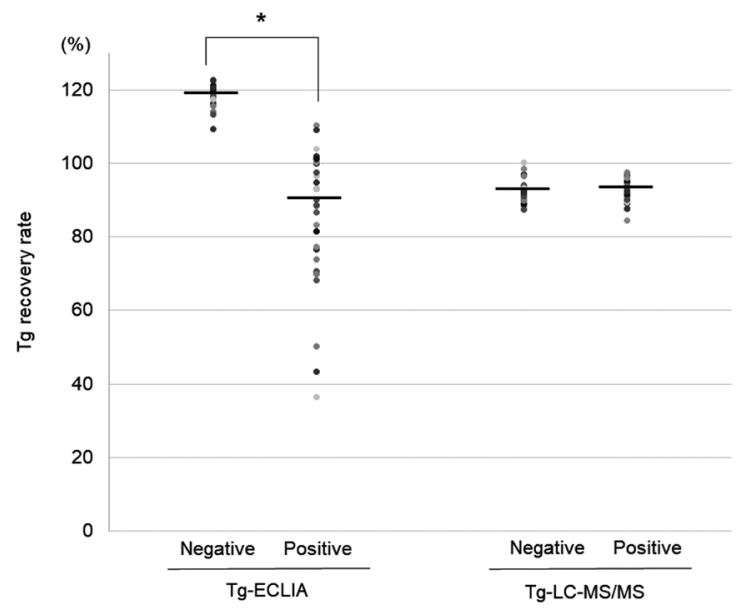

$\operatorname{TgAb}$

\section{Figure 4}

Spike-recovery test showing interference of TgAb with Tg-ECLIA but not with Tg-LC-MS/MS. A standard Tg solution $(0.5 \mu \mathrm{g} / \mathrm{mL})$ was spiked into each serum sample with $\operatorname{Tg}<0.9 \mathrm{ng} / \mathrm{mL}$ and negative $\operatorname{TgAb}(n=29)$ and to each serum sample with $\mathrm{Tg}<0.9 \mathrm{ng} / \mathrm{mL}$ and positive $\operatorname{TgAb}(n=29)$.

$\mathrm{Tg}$ recovery was calculated as (measured $\mathrm{Tg}$ concentration after addition of standard $\operatorname{Tg}(\mathrm{ng} / \mathrm{mL}) / 100 \mathrm{ng} / \mathrm{mL}) \times 100(\%)$. Bars indicate the median values. ${ }^{*} P<0.001$; negative TgAb vs positive TgAb. in approximately $40 \%$ of patients with structural disease of DTCs and low Tg values on LC-MS/MS measurement $(6,9,10)$. Higher levels of $\mathrm{TgAb}$ titers were not mainly caused by the degree of Tg underestimation (Table 2) (6).

We conducted in vitro assays to evaluate the extent of $\mathrm{TgAb}$ interference in Tg-LC-MS/MS and Tg-ECLIA assays. The interference in $\mathrm{TgAb}$ is determined by the spikerecovery test, in which a recovery of $<80 \%$ is considered a

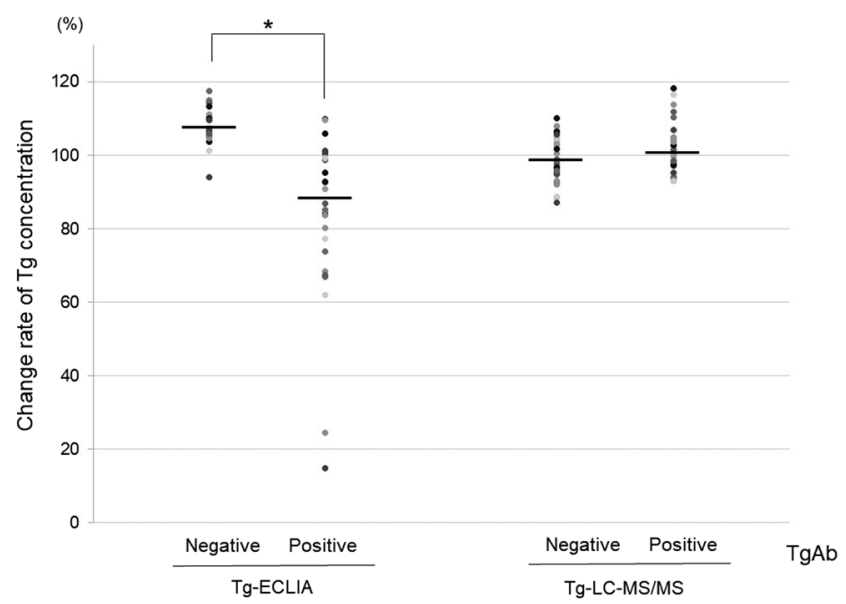

Figure 5

Serum mixture test showing interference of TgAb with Tg-ECLIA but not with Tg-LC-MS/MS. Serum samples of patients with high Tg concentration and negative $\operatorname{TgAb}(n=29)$ were mixed with equal amounts of serum samples ( $\operatorname{Tg}<0.9 \mathrm{ng} / \mathrm{mL})$ and negative $\operatorname{TgAb}(n=29)$. Similar mixtures were also performed for serum samples with $\mathrm{Tg}<0.9 \mathrm{ng} / \mathrm{mL}$ and positive $\operatorname{TgAb}(n=29)$. The change rate of $\mathrm{Tg}$ concentration was calculated as ( $T$ c concentration of the mixed samples $(\mathrm{ng} / \mathrm{mL}) \times 2 / \mathrm{Tg}$ concentration of pre-mixture $(\mathrm{ng} / \mathrm{mL})) \times 100(\%)$. Bars indicate the median values. $* P<0.001$; negative TgAb vs positive TgAb. 
positive result (11). In our study, the recovery was $75 \%$ in the Tg-ECLIA assay but almost 100\% in the Tg-LC-MS/MS assay (Fig. 4). The measured recovery is dependent on the protocol used, including the exogenous $\mathrm{Tg}$ concentration and Tg source (12). Therefore, we performed serum mixture tests using samples of various concentrations of native $\mathrm{Tg}$. With $\mathrm{TgAb}$, the Tg concentrations were significantly reduced in Tg-ECLIA but not in Tg-LC-MS/MS (Fig. 5), which supports the spike-recovery test. Our in vitro tests showed that the presence of $\mathrm{TgAb}$ rendered $\mathrm{Tg}$ values $19-25 \%$ lower than the expected value in the Tg-ECLIA assay but not in the Tg-LC-MS/MS assay, confirming TgAb interference in the immunoassay. However, the extent of the interference was too small to explain undetectable or low serum $\mathrm{Tg}$ values in patients with structural recurrence.

We confirmed the existence of $\mathrm{Tg}$ protein in metastatic lesions using immunohistochemistry and $\mathrm{Tg}$ measurement of the washout fluid, even in patients with undetectable serum Tg values. Although evaluation of washout fluid from lymph node metastasis is available for only one patient, Tg levels were almost similar in Tg-ECLIA and Tg-LC-MS/MS. Therefore, it is unlikely that serum $\mathrm{Tg}$ levels are reduced because of poorly differentiated changes in PTC.

In addition to de-differentiation, there are several possibilities for serum $\mathrm{Tg}$ to be much lower than expected in both assays. One is that $\mathrm{Tg}$ may be altered by somatic mutations in the $T G$ gene in the tumors. The other is that multimerization of $\mathrm{Tg}$ at very high concentrations reduces soluble capability and is not recognized by antibodies directed against specific Tg epitopes (13). Otherwise, disproportionally low levels of $\mathrm{Tg}$ may reflect low serum $\mathrm{Tg}$ concentrations due to the removal of $\mathrm{Tg}$ from the bloodstream by some mechanism. An accelerated metabolic clearance of $\operatorname{Tg}-\operatorname{Tg} A b$ complexes due to its greater immune elimination from the blood stream was

Table 3 Comparison of measurements by Tg-LC-MS/MS and Tg-ECLIA.

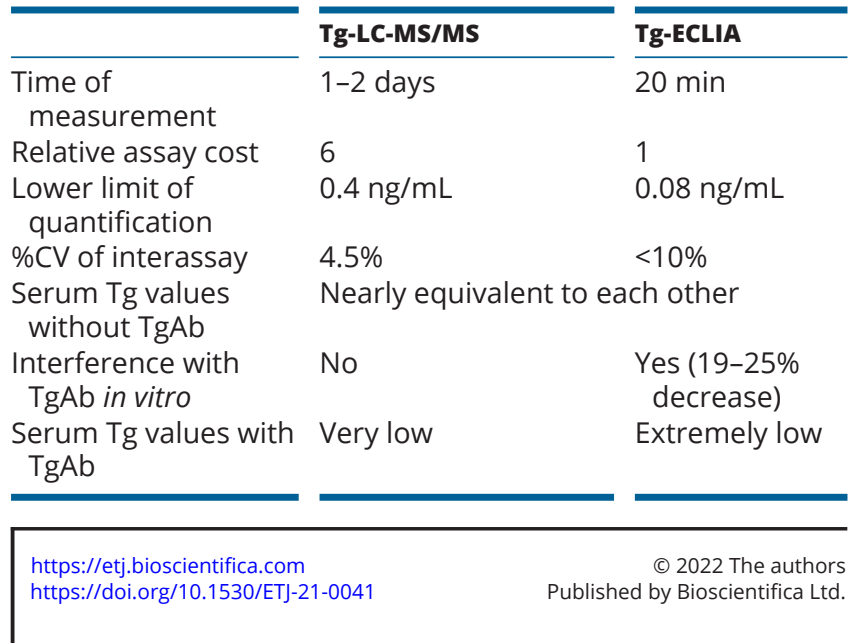

demonstrated in an animal experiment on autoimmune thyroiditis (14). Similar clinical evidence also suggests that this phenomenon plays a role in humans, wherein serum $\mathrm{Tg}$ clearance is parallel with the temporal elevation of specific $\operatorname{TgAb}$ immunoglobulin subclasses in patients with Graves' disease after radioiodine treatment $(15,16)$. However, the detailed mechanism of $\mathrm{Tg}$ clearance remains unclear.

The comparative features of Tg-LC-MS/MS and Tg-ECLIA are summarized in Table 3. In this study, we confirmed that Tg-LC-MS/MS is a valuable alternative method for evaluating $\mathrm{Tg}$ values without $\mathrm{TgAb}$ interference. In our assay, the introduction of a polyclonal antibody, with the spin-type column immobilized with protein $G$, resulted in a shorter purification time (from more than $8 \mathrm{~h}$ to only $30 \mathrm{~min}$ ), with an adequate recovery rate (approximately $80 \%$ ) before liquid chromatography, but it still requires complex and manual workflows, which is a limitation for routine application in clinical practice.

In conclusion, Tg-LC-MS/MS assay was not affected by $\mathrm{TgAb}$, while $\mathrm{Tg}$-ECLIA showed $19-25 \%$ lower values in the presence of $\mathrm{TgAb}$. Tg-LC-MS/MS is preferable for monitoring serum $\mathrm{Tg}$ levels in $\mathrm{TgAb}$-positive patients. However, TgAb-positive patients with structural recurrence often had disproportionally low $\mathrm{Tg}$ values even with the LC-MS/MS assay, indicating some mechanism of removal of $\mathrm{Tg}$ in vivo, such as elimination of the $\mathrm{Tg}-\mathrm{TgAb}$ immune complex.

\section{Supplementary materials}

This is linked to the online version of the paper at https://doi.org/10.1530/ ETJ-21-0041.

\section{Declaration of interest}

The authors declare that there is no conflict of interest that could be perceived as prejudicing the impartiality of the research reported.

\section{Funding}

This study did not receive any specific grant from any funding agency in the public, commercial, or not-for-profit sectors.

\section{Statement of ethics}

All participants provided informed consent to participate in the study. The study protocol was reviewed and approved by the Ethics Committee of Kuma Hospital (No. 20170914-10) and conducted in accordance with the principles of the Declaration of Helsinki.

This work is licensed under a Creative Commons Attribution 4.0 International License. 


\section{Author contribution statement}

$\mathrm{E} \mathrm{N}$ and $\mathrm{A} \mathrm{M}$ designed the study. E N, Y I, and Y $\mathrm{H}$ extracted the data and performed the statistical analyses. $\mathrm{EN}$ and $\mathrm{A} \mathrm{M}$ wrote the manuscript. $\mathrm{Y} \mathrm{H}$ conducted the $\mathrm{Tg}$ measurements using Tg-LC-MS/MS. $\mathrm{K} \mathrm{H}$ and $\mathrm{M} \mathrm{H}$ performed histological and immunochemical analyses. Y I, M I, S F, M N, and T A contributed to patient care and data acquisition. All the authors discussed the results and approved the final manuscript.

\section{Acknowledgement}

The authors would like to thank Ms Izumi Otsuka for extracting the data from the electronic medical chart system.

\section{References}

1 Spencer CA, Takeuchi M, Kazarosyan M, Wang CC, Guttler RB, Singer PA, Fatemi S, LoPresti JS \& Nicoloff JT. Serum thyroglobulin autoantibodies: prevalence, influence on serum thyroglobulin measurement, and prognostic significance in patients with differentiated thyroid carcinoma. Journal of Clinical Endocrinology and Metabolism 199883 1121-1127. (https://doi.org/10.1210/ jcem.83.4.4683)

2 Feldt-Rasmussen U \& Rasmussen AK. Autoimmunity in differentiated thyroid cancer: significance and related clinical problems. Hormones 20109 109-117. (https://doi.org/10.14310/horm.2002.1261)

3 Latrofa F, Ricci D, Montanelli L, Rocchi R, Piaggi P, Sisti E, Grasso L, Basolo F, Ugolini C, Pinchera A, et al. Lymphocytic thyroiditis on histology correlates with serum thyroglobulin autoantibodies in patients with papillary thyroid carcinoma: impact on detection of serum thyroglobulin. Journal of Clinical Endocrinology and Metabolism 201297 2380-2387. (https://doi.org/10.1210/jc.2011-2812)

4 Hoofnagle AN \& Roth MY. Clinical Review: Improving the measurement of serum thyroglobulin with mass spectrometry. Journal of Clinical Endocrinology and Metabolism 201398 1343-1352. (https:// doi.org/10.1210/jc.2012-4172)

5 Hoofnagle AN, Becker JO, Wener MH \& Heinecke JW. Quantification of thyroglobulin, a low-abundance serum protein, by immunoaffinity peptide enrichment and tandem mass spectrometry. Clinical Chemistry 200854 1796-1804. (https://doi.org/10.1373/ clinchem.2008.109652)

6 Netzel BC, Grebe SK, Carranza Leon BG, Castro MR, Clark PM, Hoofnagle AN, Spencer CA, Turcu AF \& Algeciras-Schimnich A. Thyroglobulin (Tg) testing revisited: Tg assays, $\mathrm{TgAb}$ assays, and correlation of results with clinical outcomes. Journal of Clinical Endocrinology and Metabolism 2015100 E1074-E1083. (https://doi. org/10.1210/jc.2015-1967)
7 Clarke NJ, Zhang Y \& Reitz RE. A novel mass spectrometry-based assay for the accurate measurement of thyroglobulin from patient samples containing antithyroglobulin autoantibodies. Journal of Investigative Medicine 201260 1157-1163. (https://doi.org/10.2310/ JIM.0b013e318276deb4)

8 Kushnir MM, Rockwood AL, Roberts WL, Abraham D, Hoofnagle AN \& Meikle AW. Measurement of thyroglobulin by liquid chromatographytandem mass spectrometry in serum and plasma in the presence of antithyroglobulin autoantibodies. Clinical Chemistry 201359 982-990. (https://doi.org/10.1373/clinchem.2012.195594)

9 Spencer C, Petrovic I, Fatemi S \& LoPresti J. Serum thyroglobulin (Tg) monitoring of patients with differentiated thyroid cancer using sensitive (second-generation) immunometric assays can be disrupted by false-negative and false-positive serum thyroglobulin autoantibody misclassifications. Journal of Clinical Endocrinology and Metabolism 2014 99 4589-4599. (https://doi.org/10.1210/jc.2014-1203)

10 Azmat U, Porter K, Senter L, Ringel MD \& Nabhan F. Thyroglobulin liquid chromatography-tandem mass spectrometry has a low sensitivity for detecting structural disease in patients with antithyroglobulin antibodies. Thyroid 201727 74-80. (https://doi. org/10.1089/thy.2016.0210)

11 Spencer C \& Fatemi S. Thyroglobulin antibody (TgAb) methods strengths, pitfalls and clinical utility for monitoring TgAb-positive patients with differentiated thyroid cancer. Best Practice and Research: Clinical Endocrinology and Metabolism 201327 701-712. (https://doi. org/10.1016/j.beem.2013.07.003)

12 Giovanella L, Feldt-Rasmussen U, Verburg FA, Grebe SK, Plebani M \& Clark PM. Thyroglobulin measurement by highly sensitive assays: focus on laboratory challenges. Clinical Chemistry and Laboratory Medicine 201553 1301-1314. (https://doi.org/10.1515/cclm-2014-0813)

13 Gérard AC, Denef JF, Colin IM \& van den Hove MF. Evidence for processing of compact insoluble thyroglobulin globules in relation with follicular cell functional activity in the human and the mouse thyroid. European Journal of Endocrinology 2004150 73-80. (https:// doi.org/10.1530/eje.0.1500073)

14 Weigle WO \& High GJ. The behavior of autologous thyroglobulin in the circulation of rabbits immunized with either heterologous or altered homologous thyroglobulin. Journal of Immunology 196798 1105-1114.

15 Latrofa F, Ricci D, Montanelli L, Piaggi P, Mazzi B, Bianchi F, Brozzi F, Santini P, Fiore E, Marinò M, et al. Thyroglobulin autoantibodies switch to immunoglobulin (Ig)G1 and IgG3 subclasses and preserve their restricted epitope pattern after 131I treatment for Graves' hyperthyroidism: the activity of autoimmune disease influences subclass distribution but not epitope pattern of autoantibodies. Clinical and Experimental Immunology 2014178 438-446. (https://doi. org/10.1111/cei.12438)

16 Latrofa F, Ricci D, Bottai S, Brozzi F, Chiovato L, Piaggi P, Marinò M \& Vitti P. Effect of thyroglobulin autoantibodies on the metabolic clearance of serum thyroglobulin. Thyroid 201828 288-294. (https:// doi.org/10.1089/thy.2017.0052)

Received in final form 22 November 2021

Accepted 7 December 2021

Accepted Manuscript published online 7 December 2021 (c) 2022 The authors Published by Bioscientifica Ltd.

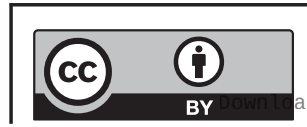

This work is licensed under a Creative Commons Attribution 4.0 International License. ded from Bioscientifica.com at 04/26/2023 10:40:25AM via free access 